\title{
RBEP
}

\section{Percursos e tendências da produção científica sobre crianças de 0 a 3 anos na Anped*}

\author{
Márcia Buss-Simão \\ Eloisa Acires Candal Rocha \\ Fernanda Gonçalves
}

http://dx.doi.org/10.1590/S2176-6681/335812912

\section{Resumo}

Resulta de um levantamento dos trabalhos apresentados no GT07: Educação de crianças de 0 a 6 anos, nas reuniões anuais da Associação Nacional de Pós-Graduação e Pesquisa em Educação (Anped), entre os anos de 2003 e 2013, com o objetivo de mapear a produção científica sobre as crianças de zero a três anos de idade. Para a busca dos trabalhos, foram definidas algumas palavras-chave: educação infantil; creche; berçário; crianças pequenas; bebês; zero (0) a três (3). A primeira busca foi realizada nos resumos e nas palavras-chave propostas no próprio artigo, e, quando necessário, recorreu-se ao trabalho completo. A partir dessa busca, foram localizados 23 trabalhos que abordavam a temática, e estes foram lidos na íntegra para categorização e análise. Com base na leitura dos trabalhos, utilizando a estratégia metodológica de análise de conteúdo, foi possível, por meio de método indutivo, agrupá-los em temáticas: "dimensão pedagógica", "perspectivas sociológicas", "políticas para educação infantil" e "história". Destaca-se que no período entre os anos de 2003 a 2013 um total de 175

* Uma versão preliminar deste texto foi apresentada como comunicação oral na Anped Sul em outubro de 2014, evento realizado na Universidade do Estado de Santa Catarina (Udesc), em Florianópolis. 
trabalhos foi apresentado no GT07, dos quais somente 23 trabalhos tiveram como preocupação as crianças de zero a três anos. Embora esse número seja muito inferior ao total, revela-se uma crescente preocupação e prioridade da área em relação à situação da creche e das crianças pequenas.

Palavras-chave: educação infantil; produção científica; zero a três.

\section{Abstract \\ Pathways and trends in the scientific literature about children aged 0-3 years in Anped}

This article results from a survey based on papers presented in the working group (GT) 07: Education of children aged 0 to 6 years, at the annual meetings of the National Association of Graduate Studies and Research in Education (Anped), between 2003 and 2013. This study aims at mapping the scientific literature on young children (from zero to three years of age). In order to refine the search, some keywords were defined: early childhood education; childcare; nursery; young children; babies; zero to three. The first search focused on abstracts and keywords proposed in the articles, besides that, when necessary, the whole paper was analyzed. From this initial search, 23 papers about the topic were read in full for categorization and analysis. Based on the reading of the articles, the methodological strategy of content analysis was applied. It was then possible, through the inductive method, to group the papers into themes: pedagogical dimension, sociological perspectives, policies for early childhood education and history. It is noteworthy that in the period between 2003 and 2013, a total of 175 papers were presented in GT07; however, only 23 papers approached topics related to children aged zero to three. Despite this number being very inferior to the total of articles, it reveals a growing concern and priority in the area regarding the situation of nursery and young children.

Keywords: early childhood education; scientific production; zero to three.

\footnotetext{
Neste texto nos ocuparemos do elemento que concerne ao atendimento das crianças de zero a três anos, no entanto, um segundo elemento, no que se refere ao atendimento às crianças de quatro a cinco anos, também nos desafia: evitar o ingresso precoce de crianças na pré-escola e no ensino fundamental nos sistemas e redes de ensino.
}

\section{Introdução}

Com a aprovação da Emenda Constitucional (EC) n 59/2009 que determina a extensão da obrigatoriedade da educação infantil para crianças a partir de quatro anos de idade, as discussões acerca da educação das crianças de zero a três anos estão em evidência em razão principalmente de um elemento desafiante nessa nova realidade: ${ }^{1}$

[...] evitar a cisão da creche e da pré-escola, sob o risco de flexibilizar o significado da creche como "atenção integral ao desenvolvimento da 
primeira infância", abrindo a possibilidade de alternativas de atendimento não formais, em espaços domésticos ou não, inadequados aos critérios educacionais, com pessoas sem formação e qualificação. (Vieira, 2011, p. 247).

O comprometimento de pesquisadores com esse desafio se manifesta por meio de um significativo aumento da produção, cujo interesse é estudar os processos educativos que envolvem as crianças dessa faixa etária, como se observa nos trabalhos apresentados nas reuniões anuais da Associação Nacional de Pós-Graduação e Pesquisa em Educação (Anped).

Esse aumento no número de trabalhos suscita questionamentos sobre o que se está produzindo sobre as crianças de zero a três anos, sob qual perspectiva teórica, a partir de quais cruzamentos, relações e articulações disciplinares. Rocha e Buss-Simão (2013), em levantamento da produção recente da Região Sul, alertam para o crescimento das pesquisas em educação, mais especificamente na educação infantil (sem que se restrinja a esse nível), que tomam como referencial a Sociologia da Infância.

Esta intensificação foi resultado da consolidação desta área na Europa, do fortalecimento das relações internacionais dos PPGE'S e da própria demanda científica por uma maior articulação disciplinar para o estudo da educação na infância. (Rocha; Buss-Simão, 2013, p. 949).

Os estudos sociais da infância trazem à tona uma nova concepção de criança, assumindo-a como ator social, ativo nas relações sociais, que produzem e reproduzem cultura. Essa mudança paradigmática influencia significativamente para que se lance um novo olhar para os bebês, que por vezes eram esquecidos e desconsiderados. Segundo Coutinho (2010), a Sociologia da Infância tem como base princípios formulados por Prout e James (1990, p. 8 apud Coutinho 2010, p. 5), que defendem:

1. A infância é entendida como uma construção social. 2. A infância é uma variável de análise social. 3. As relações sociais e culturais das crianças são dignas de estudo em seu direito próprio. 4. As crianças são e devem ser encaradas como ativas na construção e determinação de suas próprias vidas. 5. A etnografia é uma metodologia particularmente útil para o estudo da infância. 6. Ao proclamar um novo paradigma dos estudos da infância também está a empenhar-se numa reconstrução da infância na sociedade.

Esses princípios chamam a atenção para um novo jeito de compreender as crianças e suas formas de viver e agir no mundo. As crianças que eram consideradas um vir-a-ser passam a ser concebidas como atores sociais de direitos.

[...] principalmente por oposição a essa concepção da infância, considerada como um simples objeto passivo de uma socialização regida por instituições, que vão surgir e se fixar os primeiros elementos de uma sociologia da infância. (Sirota, 2001, p. 9). 
De acordo com Guimarães (2008), no Brasil as formas de relação com os bebês são marcadas por questões de caráter disciplinador, higienista e de controle. Durante muito tempo, os bebês foram concebidos como seres frágeis e imaturos, mas estudos recentes vêm apontando para a capacidade real dos bebês, dentre os quais podemos destacar as contribuições das pesquisadoras Guimarães (2008), Coutinho (2010), Tristão (2004) e Schmitt (2008). Os trabalhos sobre os bebês têm nos aproximado cada vez mais das suas formas de se comunicar e compreender o mundo.

Temos cada vez um maior conhecimento acerca da complexidade da sua herança genética, dos seus reflexos, suas competências sensoriais e, para além das suas capacidades orgânicas, aprendemos que os bebês também são pessoas potentes no campo das relações sociais e da cognição. Os bebês possuem um corpo onde afeto, intelecto e motricidade estão profundamente conectados e é a forma particular como estes elementos se articulam que vão definindo as singularidades de cada indivíduo ao longo de sua história. Cada bebê possui um ritmo pessoal, uma forma de ser e de se comunicar. (Barbosa, 2010, p. 2).

Ao se observar atentamente as crianças, com olhar sensível às suas múltiplas formas de se expressar, suas reações, suas falas e balbucios, seus olhares, seus gestos, seus movimentos, suas interações, enfim, suas vivências no cotidiano, é possível encontrar caminhos que promovam experiências significativas nas relações pedagógicas cotidianas, possibilitando que as crianças aprofundem seus conhecimentos, ampliem seus repertórios, se aproximem das linguagens da arte, da cultura, entre outros aspectos.

\section{Pesquisa em educação infantil na Anped: constituição de um campo científico}

A educação das crianças de zero a seis anos de idade apresenta-se como um campo de institucionalização recente e, ainda que exista um aumento no número de pesquisas e trabalhos que se preocupam em estudar a educação infantil, recebe pouca atenção, principalmente se ponderarmos sobre o conjunto da produção acadêmica na pós-graduação brasileira, como apontam Silva, Luz e Faria Filho (2010).

Em estudo da produção de pesquisas na área da educação infantil entre os anos de 1983 e 1998, Strenzel (2000 apud Silva; Luz; Faria Filho, 2010) identificou que a produção científica se concentrou em nível de mestrado no decorrer da década de 1990, revelando um crescimento expressivo em relação às décadas anteriores, ao passo que foi possível verificar o crescimento das teses de doutorado mais ao final do período estudado:

Entendemos que a construção da área como campo de conhecimento e seu fortalecimento no campo da educação passam também pela pesquisa institucionalizada. As transformações que vêm ocorrendo na última década no campo da pesquisa em educação no Brasil indicam a 
tendência de que, ao lado da pós-graduação stricto sensu, os grupos ou núcleos de pesquisa se constituem em espaços que promovem o avanço do conhecimento na área e a conformam, reunindo seus pesquisadores, elegendo temas, abordagens teórico-metodológicas, interfaces, etc. (Silva; Luz; Faria Filho, 2010, p. 85).

No que se refere aos estudos e às pesquisas sobre a educação na pequena infância, a constituição do Grupo de Trabalhos da Educação da Criança de 0 a 6 anos na Anped esteve ligada a um caráter político que consolidou o compromisso da associação e de seus membros com a luta pela conquista do direito à educação pública, gratuita e de qualidade para os brasileiros. A organização do grupo foi resultado de um esforço coletivo dos programas de pós-graduação em Educação do País, recém-criados, que na época tinham como objetivo: "[...] articular a produção de conhecimento sobre a educação com reflexão e definição das políticas públicas para a educação" (Rocha, 2008, p. 53).

O GT07 iniciou sua efetiva participação na Reunião Anual da Anped no ano de 1981, como resultado do expressivo movimento de discussões acerca das políticas sociais e educacionais que marcaram aquele período. ${ }^{2}$ Em sua fundação, chamava-se GT de Educação Pré-Escolar:

[...] o grupo reuniu pesquisadores e profissionais ligados à formação e aos sistemas de ensino na rede pública, com a intenção de constituir um fórum de discussões e debates dos problemas e políticas da área. Durante os primeiros anos de sua consolidação, entre as discussões que buscavam um reconhecimento da situação da educação infantil nacional, o GT organizou debates internos e reuniões de trabalho tendo em vista a definição de posicionamentos da Anped frente às novas deliberações legais que pautaram todo o cenário político desde o fim dos anos oitenta, em especial até a promulgação da LDB. (Rocha, 2008, p. 53).

O foco da luta política do grupo ficou definido como viabilização de políticas educacionais que promovessem possibilidades de efetivação dos direitos das crianças à educação infantil (Rocha, 1997 apud Rocha, 2008). Em seus primeiros anos, o GT de Educação Pré-Escolar - que depois passou a se chamar Educação de Crianças de 0 a 6 anos - procurou acompanhar a ideia geral dos grupos de trabalho, num esforço de consolidar um espaço em que questões teórico-metodológicas e resultados de pesquisas pudessem ser discutidos e refletidos.

O início do grupo coincidiu com o crescimento do tema nos programas de pós-graduação, combinado com o crescente interesse do movimento internacional pela pesquisa acerca da educação na pequena infância, que passou a aflorar a partir dos anos 70 (Rocha, 2008).

Segundo Rocha (2008), é interessante notar que nesse período existia o predomínio das pesquisas que tinham como preocupação a criança préescolar e seu desenvolvimento, embora existisse um movimento no final da década de 1990 que assinalava a consolidação das pesquisas em educação infantil
2 "Criada em 1978, a Anped só organizou os Grupos de Trabalhos em 1981, na $4^{a}$ Reunião Anual. Antes disso, realizou suas reuniões em torno de temais gerais, vinculados especialmente aos programas de pós-graduação" (Rocha, 2008, p. 53). 
[...] a partir de uma dimensão pedagógica articulada às suas dimensões contextuais. Em parte, essa consolidação pauta-se em bases históricas amplamente investigadas no período e representadas no grupo que analisam criticamente a definição das funções sociais e educativas da creche e da pré-escola. (Rocha, 2008, p. 55).

Silva, Luz e Faria Filho (2010), em pesquisa acerca dos elementos para a compreensão do processo de constituição da área de estudos sobre a infância, a criança e a educação infantil, no campo da educação, por meio de um mapeamento dos grupos e núcleos de pesquisa que estudaram e pesquisaram tais temáticas, indicam que conhecer esses grupos configura-se como estratégia importante de compreensão desse campo de estudo e pesquisa. Nesse mapeamento, os autores identificaram que 70 grupos apresentavam no título ou nas palavras-chave de suas linhas de pesquisa temas específicos da educação infantil. ${ }^{3}$

Nas frequências levantadas na pesquisa realizada por Silva, Luz e Faria Filho (2010), o tema "infância" foi o mais frequente entre as palavras-chave; em seguida apareceram os temas da "educação infantil" e da "educação" de modo geral. Já os temas referentes às "crianças", à "formação de professores" e às "políticas" foram os três que mais apareceram na sequência. Os autores ainda destacam que pesquisas e perspectivas recentes demonstram que:

[...] as temáticas, as quais até início dos anos de 1990 se centravam nos adultos e nas instituições, passaram a incluir reflexões sobre a ação social das crianças como seres históricos e culturais concretos, reprodutores e produtores de cultura. (Silva; Luz; Faria Filho, 2010).

Nesse mapeamento realizado pelos pesquisadores, temas como "creche" foram pouco frequentes se comparados com os outros, de modo que se levanta um importante questionamento: que lugar ocupam as creches e as crianças de zero a três anos nas pesquisas no campo da educação?

Em pesquisa realizada com objetivo de apresentar uma revisão da trajetória do GT07 no âmbito das reuniões anuais da Anped, nos 30 anos de sua existência, como forma de recuperar também os caminhos da pesquisa sobre educação infantil no Brasil, Rocha (2008, p. 59) constata que "permanece bastante inicial a apresentação no grupo de trabalhos que tenham como preocupação o estudo com bebês nesses contextos".

De acordo com Silva, Luz e Faria Filho (2010), existe de fato uma baixa visibilidade da área da educação infantil na pós-graduação. Ainda que as duas últimas décadas tenham se mostrado fecundas no desenvolvimento das pesquisas da área, a inserção da temática nos programas de pós-graduação ainda é consideravelmente baixa, o que remete a questões concernentes ao lugar da infância e da educação infantil no campo científico em geral, e mais particularmente no campo da educação.

No trabalho encomendado Bebês e creche: discursos e políticas, apresentado na 35 a Reunião Anual da Anped, no ano de 2012, Fúlvia Rosemberg afirma, com base em levantamento sobre a creche na base de dados da Coordenação de Aperfeiçoamento de Pessoal de Nível Superior (Capes) (1986-2011), que a creche e os bebês não são temas nacionais, ou 
seja, não aparecem como uma preocupação nacional. Além de a creche inexistir nas outras áreas do conhecimento, os estudos realizados, por vezes, mostram-na apenas como lócus de pesquisa da pediatria, principalmente aquelas que atendem crianças pobres, evidenciando concepções estigmatizadoras tanto sobre a creche como sobre os bebês. De modo geral, pode-se afirmar uma invisibilidade tanto dos bebês como também das creches. Portanto, fica uma pergunta: onde estão a creche e os bebês? ${ }^{4}$

\section{A produção científica recente: trabalhos apresentados no GT07, na Reunião Nacional da Anped, entre os anos de 2003 e 2013}

A Anped realiza reuniões anuais com intuito de estabelecer diálogos, debates e reflexões entre pesquisadores de todo o Brasil. Todos os anos, os trabalhos apresentados, na maioria das vezes oriundos das teses e dissertações, são separados por Grupos de Trabalhos (GTs), os quais reúnem temáticas e eixos de pesquisas. Trata-se de uma sociedade civil sem fins lucrativos que agrupa sócios institucionais (os programas de pós-graduação em Educação) e sócios individuais (professores, pesquisadores e estudantes de pós-graduação em Educação). Seu principal objetivo é fortalecer a pósgraduação e a pesquisa na educação brasileira.

O levantamento da produção divulgada nas reuniões anuais da Anped constituiu-se a partir da análise dos trabalhos apresentados no GT07 (Educação de crianças de 0 a 6 anos) entre 2003 e 2013 (ou seja, da 26a à $36^{\text {a }}$ Reunião Anual). Para a escolha dos trabalhos, o critério utilizado foi selecionar as pesquisas preocupadas em estudar a educação de crianças na faixa etária de zero a três anos de idade publicadas no GT. Em alguns trabalhos, foi possível reconhecer a temática e o recorte etário das crianças por meio dos próprios resumos; em outros, esses aspectos ficaram evidentes somente com a leitura do texto completo, pois no resumo nem sempre constava a informação sobre a faixa etária das crianças.

Para otimizar e refinar a busca dos trabalhos, adotamos algumas palavras-chave como recorte necessário para compor a análise. A primeira busca foi realizada nos resumos e nas palavras-chave propostas no próprio artigo, e, quando necessário, buscamos pelas palavras no corpo do texto. As palavras-chave definidas para a realização do levantamento foram: educação infantil; creche; berçário; crianças pequenas; bebês; zero (0) a três (3). O objetivo foi mapear a produção científica sobre as crianças de zero a três anos de idade, que está emergindo nessas reuniões. Após análise dos títulos, leitura dos resumos e palavras-chave, levantamos 23 trabalhos que foram selecionados como relevantes.

Interessante notar que entre os anos de 2003 e 2013 um total de 175 trabalhos foi apresentado no GT07, nas reuniões anuais da Anped, mas somente 23 tinham por objetivo estudar as crianças de zero a três anos de idade. Esse número pode ser considerado baixo se o compararmos ao total dos que se dedicaram a pensar as crianças maiores, na faixa etária de quatro a seis anos.

\footnotetext{
${ }^{4}$ Informação verbal em trabalho encomendado apresentado na $35^{\mathrm{a}}$ Reunião da Anped, no GT07, em 22 de outubro de 2012 .
} 


\section{Quadro 1 - Títulos dos Trabalhos Selecionados}

\begin{tabular}{|c|c|c|}
\hline $\mathrm{N}^{\circ}$ & Autor/Co-autor & Título \\
\hline 1 & ALCÂNTARA, Cássia V. M. de (UFS) & Aventuras no país das maravilhas foucaultianas (2005) \\
\hline 2 & $\begin{array}{l}\text { OLIVEIRA, Fabiana de; } \\
\text { ABRAMOWICZ, Anete (UFSCar) }\end{array}$ & $\begin{array}{l}\text { A 'paparicação' na creche enquanto uma prática que inviabiliza } \\
\text { a construção de uma educação da 'multidão' (2005) }\end{array}$ \\
\hline 3 & $\begin{array}{l}\text { MACEDDO, Lenilda Cordeiro de; } \\
\text { DIAS, Adelaide Alves (UFPB) }\end{array}$ & $\begin{array}{l}\text { O cuidado e a educação enquanto práticas indissociáveis na } \\
\text { educação infantil (2006) }\end{array}$ \\
\hline 4 & ALCÂNTARA, Cássia V. M. de (UFS) & $\begin{array}{l}\text { Subjetividade e subjetivação: a "criança resistência" nas dobras } \\
\text { do processo de socialização (2006) }\end{array}$ \\
\hline 5 & GUIMARÃES, Daniela (PUC-Rio) & $\begin{array}{l}\text { Entre a instrução e o diálogo: a construção da identidade } \\
\text { educacional das creches (2006) }\end{array}$ \\
\hline 6 & $\begin{array}{l}\text { ROCHA LIMA, Ana Beatriz (Univali); } \\
\text { BHERING, Eliana (FE/UFRJ) }\end{array}$ & $\begin{array}{l}\text { Creche como contexto de desenvolvimento: um estudo sobre o } \\
\text { ambiente de creches em um município de SC (2006) }\end{array}$ \\
\hline 7 & $\begin{array}{l}\text { BHERING, Eliana; } \\
\text { SARKIS, Alessandra (UFRJ) }\end{array}$ & $\begin{array}{l}\text { A inserção de crianças na creche: um estudo sobre a } \\
\text { perspectiva dos pais (2007) }\end{array}$ \\
\hline 8 & $\begin{array}{l}\text { GUIMARÃES, Daniela de O. (PUC- } \\
\text { Rio) }\end{array}$ & $\begin{array}{l}\text { No contexto da creche, o cuidado como ética e a potência dos } \\
\text { bebês (2008) }\end{array}$ \\
\hline 9 & MARTINS, Rosimari Koch (UFSC) & $\begin{array}{l}\text { As experiências educativas das crianças menores de quatro } \\
\text { anos, do meio rural (2009) }\end{array}$ \\
\hline 10 & CAMPOS, Roselane Fátima (UFSC) & $\begin{array}{l}\text { A educação infantil no contexto pós-reforma: } \\
\text { institucionalização e regulação no Brasil e Argentina (2009) }\end{array}$ \\
\hline 11 & $\begin{array}{l}\text { SANTOS, Cláudia Amaral dos } \\
\text { (UFRGS) }\end{array}$ & $\begin{array}{l}\text { A vida do bebê: a constituição de infâncias saudáveis e normais } \\
\text { nos manuais de puericultura brasileiros (2010) }\end{array}$ \\
\hline 12 & MARTINS, Rosimari Koch (SED-SC) & $\begin{array}{l}\text { Expectativas das famílias do meio rural em relação à educação } \\
\text { pública para os filhos menores de quatro anos (2011) }\end{array}$ \\
\hline 13 & RAMOS, Tacyana Karla Gomes (UFS) & $\begin{array}{l}\text { Possibilidades de organização de práticas educativas na creche } \\
\text { em parceria com os bebês: o que "dizem" as crianças? (2011) }\end{array}$ \\
\hline 14 & CASANOVA, Letícia Veiga (Univali) & $\begin{array}{l}\text { O que as crianças pequenas fazem na creche? As famílias } \\
\text { respondem (2011) }\end{array}$ \\
\hline 15 & $\begin{array}{l}\text { SIMIANO, Luciane Pandini; } \\
\text { VASQUES, Carla Karnoppi (UFRGS) }\end{array}$ & $\begin{array}{l}\text { Sobre importâncias, medidas e encantamentos: o percurso } \\
\text { constitutivo do espaço da creche em um lugar para os bebês } \\
\text { (2011) }\end{array}$ \\
\hline 16 & DAGNONI, Ana Paula Rudolf (Univali) & Quais as fontes de saberes das professoras de bebês? (2012) \\
\hline 17 & RAMOS, Tacyana Karla Gomes (UFS) & $\begin{array}{l}\text { As crianças no centro da organização pedagógica: o que os } \\
\text { bebês nos ensinam? Qual a atuação de suas professoras? (2012) }\end{array}$ \\
\hline 18 & BUSS-SIMÃO, Márcia (Nupein/UFSC) & $\begin{array}{l}\text { Meninos entre meninos num contexto de educação infantil: } \\
\text { um olhar sobre as relações sociais de gênero na perspectiva de } \\
\text { crianças pequenas (2012) }\end{array}$ \\
\hline 19 & MATTOS, Maria N. de S. S. de (UFRJ) & Leitura literária na creche: o livro entre olhar, corpo e voz (2013) \\
\hline 20 & REIS, Lucilaine Maria da Silva (UFF) & $\begin{array}{l}\text { Inserção e vivências cotidianas: como crianças pequenas } \\
\text { experienciam sua entrada na educação infantil? (2013) }\end{array}$ \\
\hline 21 & CASTRO, Joselma Salazar de (UFSC) & $\begin{array}{l}\text { A constituição da linguagem entre os e dos bebês no espaço } \\
\text { coletivo da educação infantil (2013) }\end{array}$ \\
\hline 22 & $\begin{array}{l}\text { TEBET, Gabriela Guarnieri de } \\
\text { Campos; ABRAMOWICZ, Anete } \\
\text { (UFSCar) }\end{array}$ & $\begin{array}{l}\text { Constituindo o bebê como um conceito teórico no interior da } \\
\text { Sociologia da Infância (2013) }\end{array}$ \\
\hline 23 & $\begin{array}{l}\text { COUTINHO, Angela Maria Scalabrin } \\
\text { (UFPR) }\end{array}$ & $\begin{array}{l}\text { As relações sociais dos bebês na creche: um estudo numa } \\
\text { perspectiva sociológica (2013) }\end{array}$ \\
\hline
\end{tabular}

Fonte: Levantamento das pesquisadoras. 
Esses dados corroboram os levantados na pesquisa de Rocha (2008), já mencionada anteriormente, a qual indica que os trabalhos sobre bebês eram ainda incipientes no período por ela analisado. Da mesma forma, Silva, Luz e Faria Filho (2010) indicam que entre os temas menos frequentes nas pesquisas dos grupos de pesquisa nacionais encontra-se a creche.

Mas, afinal, é possível falar em invisibilidade tanto dos bebês como das creches? Com a obrigatoriedade da frequência regular das crianças de quatro anos de idade, agrava-se a apreensão com a situação de crianças de zero a três anos de idade. Segundo Vieira (2011), tal implementação motiva um necessário debate acerca dos desafios, que concernem, principalmente, à oferta das creches e pré-escolas, bem como à qualidade do atendimento desses estabelecimentos, considerando as condições objetivas que vivemos atualmente no País.

Embora o número de trabalhos sobre as crianças de zero a três anos seja muito inferior ao total, os números das últimas reuniões da Anped são otimistas e expressam a preocupação da área acerca da situação da creche e das crianças pequenas. $\mathrm{Na} 26^{\mathrm{a}}$ e na $27^{\mathrm{a}}$ Reuniões não foram localizados trabalhos que tenham realizado pesquisa com crianças nessa faixa etária, no entanto, houve cinco trabalhos na $36^{\mathrm{a}}$ Reunião, em 2013, como podemos observar no Quadro 2.

\section{Quadro 2 - Número de Trabalhos do GT07 por Reunião}

\begin{tabular}{|c|c|}
\hline Reunião da Anped/Ano & Número de trabalhos \\
\hline 26ª Reunião Anual - 2003 & - \\
\hline $27^{a}$ Reunião Anual - 2004 & - \\
\hline 28 $8^{\mathrm{a}}$ Reunião Anual - 2005 & 2 \\
\hline 29a Reunião Anual - 2006 & 4 \\
\hline 30 Reunião Anual - 2007 & 1 \\
\hline $31^{\mathrm{a}}$ Reunião Anual - 2008 & 1 \\
\hline 32 & 2 \\
\hline 33a Reunião Anual - 2010 & 1 \\
\hline 34ª Reunião Anual - 2011 & 4 \\
\hline 35 & 3 \\
\hline 36 $6^{\text {a }}$ Reunião Anual - 2013 & 5 \\
\hline Total de trabalhos & 23 \\
\hline
\end{tabular}

Fonte: Levantamento das pesquisadoras.

Nota: Nesse período, foram apresentados, ao todo, 175 trabalhos.

Um dado significativo nessa trajetória é que até 2008 um grande número de pesquisas se propôs a estudar questões gerais sobre a educação infantil, abrangendo a faixa etária de zero a seis anos e incluindo as 
crianças de zero a três por meio de afirmativas como a de que a pesquisa havia privilegiado crianças maiores, mas os dados poderiam ser estendidos para crianças menores. Nesse período, também é possível evidenciar que, quando as pesquisas eram realizadas com crianças de zero a três anos, os trabalhos focavam-se mais nos contextos de educação de zero a três e no termo "creche" do que nos bebês em si.

A partir do ano de 2008, o termo "bebê" surge como grande tendência na definição das pesquisas que se ocuparam das crianças dessa faixa etária - tendência que permanece nos trabalhos apresentados até 2013. Além dessa propensão ao uso da denominação "bebês", as pesquisas mostram a disposição em delimitar a faixa etária entre zero e três anos, superando a tendência em pesquisar questões gerais sobre a educação infantil de zero a seis. Poderíamos dizer que, gradativamente, as pesquisas passaram de uma perspectiva que procurava incluir marginalmente os bebês, para uma perspectiva que passa a privilegiar ou priorizar os bebês.

\section{Perspectivas de pesquisas sobre as crianças de zero a três anos na Anped}

A busca entre os anos de 2003 e 2013 nas reuniões anuais do GT07 resultou no levantamento de um total de 23 trabalhos que abordavam a temática das crianças de zero a três anos de idade, que foram lidos na íntegra para categorização e análise. Com base nessa análise qualitativa das indicações contidas nos textos, esboçamos algumas categorias analíticas. Revisitando a experiência de organização dos dados em outras pesquisas realizadas, utilizamos a estratégia metodológica de análise de conteúdo, em que, por meio de um método indutivo (Vala, 1999), as categorias pudessem emergir do campo e do agrupamento das unidades de sentido. A partir da leitura dos trabalhos foi possível agrupá-los em temáticas: "dimensão pedagógica", "perspectivas sociológicas", "políticas para educação infantil" e "história".

De acordo com Rocha e Buss-Simão (2013), análises acerca da trajetória da pesquisa na área de educação infantil realizadas nos últimos anos possibilitam chamar a atenção para uma perspectiva de consolidação de avanços relacionados aos diálogos disciplinares e teóricos

[...] na direção do que temos chamado de uma pedagogia da infância ou, se preferirem, de uma ciência da educação que tem como foco os processos educativos que envolvem as crianças - com negação às análises que as tomam como indivíduos isolados em uma abstração social e cultural. (Rocha; Buss-Simão, 2013, p. 948).

Esse diálogo e essa colaboração disciplinares já constatados na análise da produção científica da Região Sul, no âmbito dos programas de pósgraduação, pelas pesquisadoras Rocha e Buss-Simão, também puderam ser evidenciados nos trabalhos sobre crianças de zero a três anos apresentados no GT07, nas reuniões anuais da Anped entre 2003 e 2013. 
Dentre a grande interlocução disciplinar com múltiplos referenciais, podemos destacar contribuições da Antropologia, Filosofia, História, Sociologia da Infância, Psicologia e Psicologia Histórico-Cultural. São muitos autores que oferecem seu significativo contributo, entre os quais aparecem Moysés Kuhlmann Jr, Walter Kohan, Michel Foucault, Mikhail Bakhtin, Walter Benjamin, Manuel Sarmento, Eric Plaisance, Clépâtre Montandon, Manuel Pinto, Willian Corsaro, Alan Prout, Gilles Deleuze, Cliffor Geertz, Marcel Mauss, Clarice Cohn, David Le Breton, Peter Moss, Jean Piaget, Henri Wallon, Lev Vygotsky, Maria Clotilde Rossetti-Ferreira, por exemplo. No âmbito da Educação as principais referências utilizadas foram: Maurice Tardif, Bernadete Gatti, Ana Beatriz Cerisara, Maria Malta Campos, Sônia Kramer, Fúlvia Rosemberg, Ana Lúcia Goulart de Faria, Eloisa Rocha e Maria Carmen Silveira Barbosa. Esse necessário diálogo expressa a heterogeneidade como um elemento constitutivo da infância:

Mesmo representando uma forte tendência, também em termos mundiais, a perspectiva de colaboração disciplinar para uma compreensão mais articulada dos processos sociais e culturais que determinam a infância ainda está longe de ser hegemônica. Importa salientar que esse crescimento vem acompanhado de intensas mudanças conceituais na área. (Rocha; Buss-Simão, 2013, p. 948).

Da mesma forma, Sarmento (2013, p. 14), em texto publicado recentemente, indica que a

[...] abordagem interdisciplinar da infância conheceu, nas últimas décadas, um considerável progresso; não obstante, sua visibilidade pública não é equivalente a esse progresso, seu reconhecimento como campo de estudos autônomo e diferenciado tendo vindo a percorrer um caminho semeado de obstáculos.

O maior número de trabalhos, 17, foi agrupado na temática "dimensão pedagógica", que envolve as relações da pesquisa com a realidade educacional e abarca dimensões distintas, mas pertencentes ao mesmo processo social educativo. Entre as preocupações abordadas nas pesquisas podemos apontar: especificidades da docência com bebês; organização dos espaços e do tempo; ampliação das reflexões sobre o cuidado; linguagem; literatura; relações com as famílias; relações étnico-raciais; inserção e crianças atendidas no meio rural. Entre os principais focos das pesquisas, podemos localizar temas já indicados por Rocha e Buss-Simão (2013, p. 950):

Dentre os principais focos de pesquisa encontramos uma ampliação e um aprofundamento daqueles eixos teóricos, já indicados desde os anos noventa como consensuais na área da educação infantil, que deram origem a uma consolidação do que chamamos de uma pedagogia da infância. Dentre os eixos enfatizados naquele período, destacavam-se: a infância e seus direitos; as relações sociais; a linguagem; a brincadeira; a mediação; a organização do espaço e do tempo na prática pedagógica da educação infantil; a relação educação e cuidado e, posteriormente, a cultura infantil; a participação; a diversidade cultural etc. 
A perspectiva de uma Pedagogia da Infância, dentro da área da educação infantil, indicada pelas autoras referenciadas, tem por foco a necessidade de uma pedagogia que contemple as especificidades da educação de crianças de zero a seis anos de idade como balizadora da ação docente nos processos educativos e busca privilegiar, no campo investigativo, análises que envolvam as crianças e seus contextos sociais e culturais, negando as análises que concebam as crianças como indivíduos isolados em uma abstração social e cultural. As investigações apresentadas na Anped reúnem um conjunto de preocupações, temáticas e opções metodológicas que manifestam esse movimento teórico.

A temática "perspectivas sociológicas", a segunda mais frequente, apresentou um total de quatro trabalhos, os quais buscam explorar a potencialidade das relações sociais entre as crianças pequenas, bem como as relações entre as crianças e os adultos com base em uma perspectiva sociológica.

Dois dos estudos, além de indicarem as brincadeiras e a organização dos espaços e dos tempos como centrais nas possibilidades e nos limites das ações e relações sociais entre as crianças de zero a três anos de idade no contexto de creche, afirmam e evidenciam a centralidade do corpo na constituição dessas ações e relações.

O corpo, por meio do gênero, ocupa uma centralidade nas ações sociais das crianças e pode se configurar como possibilidade e como limite da sua ação social no contexto de creche. Os trabalhos indicam que o gênero ocupa uma dimensão central na ação das crianças e, além disso, o corpo se revelou central como linguagem e comunicação na medida em que as relações e a significação da ação do outro passavam pela comunicação corporal. Assim, a expressividade corporal para as crianças e para os adultos dar-se-ia de modo diferenciado, uma vez que para elas o corpo ocupa um lugar central em sua ação.

Um dos textos agrupados na temática "perspectivas sociológicas" realizou uma pesquisa qualitativa de caráter teórico que teve por objetivo problematizar a utilização de conceitos e metodologias para o estudo dos bebês, propostos pela Sociologia da Infância, tais como os conceitos de infância, geração e culturas de pares. Nesse estudo, as autoras afirmam a necessidade de se constituir teoricamente o bebê como um conceito e uma categoria analítica independente; defendem a ideia de que os bebês não devem ser estudados com base nos mesmos aportes teóricos, conceitos e metodologias utilizados para o estudo das crianças, pois compreendem que um bebê não é uma criança.

De modo geral, os estudos que se preocuparam com "dimensão pedagógica" e "perspectivas sociológicas" se constituíram, em grande número, como pesquisas de campo que adotaram procedimentos metodológicos, tais como observações participantes, registro escrito, registros fílmicos e fotográficos oriundos da etnografia. Dedicam-se às teorizações e às análises das falas e dos sentidos dados pelas crianças às suas próprias experiências em diferentes contextos sociais e educativos. 
Assumem como objetivo captar as muitas formas de as crianças se expressarem por meio das linguagens oral e corporal, num esforço de aproximação ao ponto de vista dos bebês sobre a organização das práticas educativas e suas formas de ação e relação social nesse contexto coletivo de educação.

A produção recente, tanto nesse levantamento como no realizado por Rocha e Buss-Simão (2013), tem evidenciado a contribuição e a aproximação disciplinar dos estudos sociais da infância, cabendo aqui o alerta e desafio contemporâneo, que consiste precisamente em afirmar esse campo:

[...] como área científica não apenas legítima, mas influente na produção do conhecimento sobre as crianças e, por consequência fundante de uma renovada reflexibilidade institucional sobre a infância, com incidência nas propostas políticas, e, entre elas nas políticas educativas, na formação de professores e na fundamentação da intencionalidade educativa nas escolas e creches. (Sarmento, 2013, p. 14).

O alerta é fundamental, pois o levantamento dos estudos realizados indica que buscam, sobretudo, compreender as possibilidades e especificidades que envolvem as relações educativas com as crianças bem pequenas, a potencialidade nas relações sociais entre as próprias crianças, e, entre elas e outros adultos. Para que esse conhecimento seja fundante e tenha uma incidência nos contextos coletivos de educação da pequena infância, ele precisa estar presente tanto no âmbito das propostas políticas, das políticas educativas e da formação de professores quanto no âmbito do cotidiano, de modo a fundamentar a intencionalidade educativa em creches e pré-escolas.

Nas temáticas agrupadas sob as denominações "políticas para educação infantil" e "história" houve, para cada uma delas, somente um trabalho. O estudo que se dedicou a investigar as políticas para educação infantil objetivou analisar estratégias políticas tomadas para responder às demandas sociais para a educação das crianças pequenas, em especial, às tensões e demandas que se referem à creche. O estudo assinala a carência de pesquisas que revelem a real situação sobre as relações entre a esfera pública e a privada, além de apontar que a pressão por suprir a demanda de vagas na pré-escola em decorrência da aprovação da EC no 59/2009 - que determina a extensão da obrigatoriedade para a educação infantil (Brasil, 2009) - tem levado muitos municípios a diminuir o número de vagas para as crianças de zero a três anos nas instituições públicas, reorientando sua ação para a ampliação dos convênios.

Por fim, o trabalho que definimos segundo a temática "história" centrou-se na análise de um manual de puericultura brasileiro e procurou evidenciar a constituição de infâncias saudáveis e normais. Sabemos que esses manuais, durante muito tempo, assumiram uma função pedagógica entre pais e mães, constituindo-se como conhecimento norteador para pensar a educação de bebês durante a história da organização do atendimento coletivo a essa faixa etária no Brasil. 


\section{Considerações finais}

Na trajetória desses 10 anos do levantamento de produção no GT07 da Anped pode-se observar que, além da tendência ao uso da denominação "bebês" ao invés de somente o emprego do contexto "creche", as pesquisas mostram uma disposição em delimitar seus estudos especificamente a crianças em idade de zero a três anos.

A grande maioria dos trabalhos apresenta uma perspectiva de colaborações disciplinares e teóricas com foco nos processos educativos que envolvem as crianças bem pequenas, para as quais a dimensão dos cuidados que envolvem o corpo se faz mais presente. As discussões sobre o corpo, agora também sob uma perspectiva social e não mais estritamente biológica, mostram-se como um importante elemento para a especificidade da ação docente.

Outra evidência importante é o movimento que se manifesta nos trabalhos que buscam utilizar metodologias de pesquisas que se aproximem dos modos próprios das crianças. Para isso, dedica-se às teorizações e às análises das falas e dos sentidos dados pelas crianças às suas próprias experiências.

A necessidade de identificação da produção científica relativa à educação da criança de zero a três anos de idade tem sido posta como uma exigência não só no sentido de orientar novas investigações como também de ampliar o acesso à informação em todos os âmbitos de atuação na educação infantil. Portanto, estudos como levantamentos de produção científica podem tanto contribuir com a elaboração de uma política consistente de atendimento à criança pequena quanto orientar reivindicações, implantação e avaliação de programas.

As recentes mudanças legais e políticas relativas à organização da educação básica têm apresentado novos desafios para a educação infantil, em particular, a definição da obrigatoriedade de matrícula aos quatro anos. Entretanto, a pressão para suprir a demanda de vagas na pré-escola pode levar muitos municípios a diminuir o número de vagas para as crianças de zero a três anos nas instituições públicas. Advertimos que aqui reside um alerta para a necessidade de acompanhar e conhecer essas realidades nos municípios a partir de 2014, quando a Emenda Constitucional n 59/2009 passou a vigorar.

\section{Referências bibliográficas}

BARBOSA, Maria Carmen Silveira. As especificidades da ação pedagógica com os bebês. Porto Alegre, 2010. Disponível em: <http:// portal.mec.gov.br/index.php?Itemid=1096\&id=15860\&option $=$ com content\&view $=$ article $>$. Acesso em: 27 jan. 2013. 
BRASIL. Constituição (1988). Emenda Constitucional no 59, de 11 de novembro de 2009. Diário Oficial da União, Brasília, DF, 12 nov. 2009. Disponível em: <http://www.planalto.gov.br/ccivil_03/constituicao/ Emendas/Emc/emc59.htm>. Acesso em: 27 jan. 2013.

COUTINHO, Angela Maria Scalabrin. A ação social dos bebês: um estudo etnográfico no contexto da creche. 2010. $291 \mathrm{f}$. Tese (Doutorado em Estudos da Criança) - Instituto de Educação, Universidade do Minho, Braga, 2010.

GUIMARÃES, D. O. Relações entre adultos e crianças no berçário de uma creche pública na cidade do Rio de Janeiro: técnicas corporais, responsividade, cuidado. 2008. 222 f. Tese (Doutorado em Educação) - Departamento de Educação, Pontifícia Universidade Católica, Rio de Janeiro, 2008.

ROCHA, Eloisa Acires Candal. 30 anos da educação infantil na Anped: caminhos da pesquisa. Zero a Seis, Florianópolis, v. 1, n. 17, jan./jun. 2008.

ROCHA, Eloísa Acires Candal; BUSS-SIMÃO, Márcia. Infância e educação: novos estudos e velhos dilemas da pesquisa educacional. Educação e Pesquisa, São Paulo, v. 39, n. 4, p. 943-954, 2013.

ROSEMBERG, Fúlvia. Bebês e creche: discursos e políticas. In: REUNIÃO ANUAL DA ANPED, 35. 2012, Porto de Galinhas, PE. Anais... [online] 2012. GT7: Educação de crianças de 0 a 6 anos.

SARMENTO, Manuel Jacinto. A sociologia da infância e a sociedade contemporânea: desafios conceituais e praxeológicos. In: ENS, Romilda Teodora; GARANHANI, Marynelma Camargo. Sociologia da infância e a formação de professores. Curitiba: Champagnati, 2013. p. 13-46.

SCHMITT, Rosinete V. "Mas eu não falo a língua deles!": as relações sociais de bebês num contexto de educação infantil. 2008. $217 \mathrm{f}$. Dissertação (Mestrado em Educação) - Centro de Ciências da Educação, Universidade Federal de Santa Catarina, Florianópolis, 2008.

SILVA, Isabel de Oliveira e; LUZ, Iza Rodrigues da; FARIA FILHO, Luciano Mendes de. Grupos de pesquisa sobre infância, criança e educação infantil no Brasil: primeiras aproximações. Revista Brasileira de Educação, Rio de Janeiro, v. 15 n. 43, p. 84-98, jan./abr. 2010.

SIROTA, Régine. A emergência de uma sociologia da infância: evolução do objeto, evolução do olhar. Cadernos de Pesquisa, São Paulo, n. 112, p. 7-31, mar. 2001. 
TRISTÃO, Fernanda. Ser professora de bebês: um estudo de caso de uma creche conveniada. 2004. 205 f. Dissertação (Mestrado em Educação) Centro de Ciências da Educação, Universidade Federal de Santa Catarina, Florianópolis, 2004.

VALA, Jorge. A análise de conteúdo. In: SILVA, Augusto Santos; PINTO, José Madureira (Org.). Metodologia das ciências sociais. 10. ed. Porto: Afrontamento, 1999. p. 101-128.

VIEIRA, Lívia Maria Fraga. Obrigatoriedade escolar na educação infantil. Revista Retratos da Escola, Brasília, DF, v. 5, n. 9, p. 245-262, jul./dez. 2011.

Márcia Buss-Simão, doutora em Educação pela Universidade Federal de Santa Catarina (UFSC), é professora permanente no Programa de PósGraduação em Educação da Universidade do Sul de Santa Catarina (Unisul) e pesquisadora do Núcleo de Estudos e Pesquisas da Educação na Pequena Infância (Nupein/UFSC), Tubarão, Santa Catarina, Brasil.

marcia.buss@pq.cnpq.br

Eloisa Acires Candal Rocha, doutora em Educação pela Universidade Estadual de Campinas (Unicamp), é professora titular no Centro de Educação da Universidade Federal de Santa Catarina (CED/UFSC) e no Programa de Pós-Graduação em Educação da UFSC, Florianópolis, Santa Catarina, Brasil. eloisa.rocha@ufsc.br

Fernanda Gonçalves, mestranda no Programa de Pós-Graduação em Educação da Universidade Federal de Santa Catarina (UFSC), é pesquisadora do Núcleo de Estudos e Pesquisas da Educação na Pequena Infância (Nupein/ UFSC), Florianópolis, Santa Catarina, Brasil.

feegoncalves@gmail.com

Recebido em 14 de maio de 2014.

Solicitação de correções em 10 de novembro de 2014.

Aprovado em 26 de novembro de 2014. 